This paper is published in the open archive of Mid Sweden University

DIVA http://miun.diva-portal.org

with permission of the publisher

Citation for the peer-reviewed published paper:

Eriksson M, Pettersson G, Wågberg L. Application of polymeric multilayers of starch onto wood fibres to enhance strength properties of paper. Nordic Pulp \& Paper Research Journal. 2005;20(3):270-275.

URL to article at publishers site:

http://dx.doi.org/10.3183/NPPRJ-2005-20-03-p270-276 


\section{Application of polymeric multilayers of starch onto wood fibres to enhance strength properties of paper}

Malin Eriksson, Royal Institute of Technology, KTH, Stockholm, Sweden, Gunilla Pettersson, Mid Sweden Univeristy, Sundsvall, Sweden, Lars Wågberg, Royal Institute of Technology, KTH, Stockholm, Sweden

KEYWORDS: Polyelectrolyte, Multilayer, Adsorption, Optical reflectometry, Potato starch, Anionic starch, Cationic starch, Paper strength

SUMMARY: Polyelectrolyte multilayers of cationic and anionic starch have been used to enhance the strength properties of paper. All starches used in this investigation had a degree of substitution around 0.065 . Optical reflectometry showed that a combination of cationic and anionic starch could form polyelectrolyte multilayers onto silicon oxide surfaces. The same combination of starches was then applied to unbeaten, bleached softwood kraft fibres to form three layers, i.e. a cationic/anionic/cationic starch combination. The results showed a significant increase in the paper strength properties in terms of tensile index, strain at break, and Scott Bond. The adsorbed amount of starch in the sheets, determined using an enzymatic method, was found to increase with each successive starch treatment. The increased paper strength was not only due to the increase in adsorbed amount of starch; rather, the chemical composition of the starch was also important. Cationic starch with high amylose content had a more positive effect on the paper strength properties. Furthermore, it was observed that anionic starch, despite being adsorbed in large amounts, did not contribute to the increase in tensile strength or strain at break to the same extent as did cationic starch. However, the out-ofplane properties, measured as Scott Bond properties, increased with the adsorbed amount, regardless of the chemical composition of the starch used in the outermost layer.

ADDRESSES OF THE AUTHORS: Malin Eriksson (maline@polymer.kth.se) and Lars Wågberg

(wagberg@pmt.kth.se): Royal Institute of Technology, KTH, School of Chemical Science and Engineering, Department of Fibre and Polymer Technology, KTH, SE-100 44 Stockholm, Sweden. Gunilla Pettersson (gunilla.pettersson@mh.se): Mid Sweden University, Natural and Environmental Sciences, Fibre Science and Communication Network, SE-851 70 Sundsvall, Sweden.

The significant strength-enhancing properties of cationic starch (CS) have been demonstrated in a number of published studies, such as (Lindström and Floren 1984, Retulainen et al. 1993, Howard and Jowsey1989, Moeller1966, Formento et al.1994, Laleg et al. 1991, Gaspar 1982). In systems containing high concentrations of dissolved and colloidal material from the raw wood, CS also acts as an efficient fixing agent (Wågberg and Kolar 1996). This, together with its low cost, makes it the most commonly used strength enhancer for paper.

Despite its wide use, surprisingly little is known about the molecular mechanism responsible for the efficiency of starch as a paper strength enhancer. It is, however, believed that it increases the molecular contact area and/or number of efficient fibre-fibre joints (Moeller 1966, Howard and Jowsey1989, Formento et al.1994). Better known is the mechanism - an ion-exchange process - by which cationic starch is adsorbed onto cellulose-based surfaces (van de Steeg et al.1993a, van de Steeg et al. 1993b, Wågberg and Kolar 1996, Wågberg and Björklund 1993). Thus, an increased charge on the starch leads to a lower saturation adsorption. This in turn means that the maximum enhancement that can be achieved is lower, since it is known that efficiency of starch as strength enhancer is linked to the adsorbed amount (Lindström and Floren 1984). One way of increasing the adsorbed amount of CS is by adding an anionic polyacrylamide (A-PAM) after the addition of CS (Lindström and Floren 1984). By using this approach, a considerable fraction of the starch in the sheet will probably be present in the form of polyelectrolyte complexes (PEC) of A-PAM and CS.

It has fairly recently been found that it is possible to form polyelectrolyte multilayers (PEM) on charged surfaces by means of the sequential addition of oppositely charged polyelectrolytes (Decher 1997). This has proven itself to be a promising new surface engineering technique for a wide variety of applications, such as sensor technology (Sun et al. 1996). It is also possible to improve paper strength by applying this technique to fibres (Wågberg et al. 2002). In this work polyallylamine hydrochloride $(\mathrm{PAH})$ and polyacrylic acid (PAA) were used. However, because of their high cost, these polyelectrolytes will have limited application in practical papermaking. Hence, it was considered important to test whether the multilayer concept could be adapted to various types of modified starches.

The present paper summarises the results achieved using four different starches. The anionic starch (AS) was a sulphonated potato starch. The three cationic starches (CS) were quaternary potato starches with different ratios of amylose and amylopectin. These starches were tested with regard to their ability to form PEM onto silicon oxide surfaces and fibres, and their ability to improve paper strength.

\section{Experimental}

\section{Materials}

Fibres: The fibres used in this investigation were dried, fully bleached, totally chlorine free (TCF) softwood kraft fibres from the Östrand Mill, SCA, Sundsvall, Sweden. Silicon wafers: The silicon wafers (150 mm, p-type) were purchased from Memc Electronics Materials, Novara, Italy. They were washed consecutively with ethanol and milli-Q water, blown dry with nitrogen, and oxidised in an oven at $1000^{\circ} \mathrm{C}$ for 3 hours. Before use, they were rinsed consecutively with ethanol and milli-Q water and 
blown dry with nitrogen. The silicon oxide surfaces $\left(\mathrm{SiO}_{2}\right)$ were then hydroxylated to obtain a fully wetted surface $(\mathrm{SiOH})$ by placing them in 10 wt $\%$ of $\mathrm{NaOH}$ aqueous solution for 30 seconds. They were then rinsed with plenty of milli-Q water and blown dry with nitrogen. The surface roughness did not change significantly during this step, as determined using AFM imaging (tapping mode, Picoforce SPM, Veeco Inc.). Finally, the oxidised silicon wafers were treated in a plasma cleaner (Model PDC 002, Harrick Scientific Corporation) for 30 seconds to remove any surface contaminants. The thickness of the oxide layer on each strip was measured using a Rudolph ellipsometer, model 437, revealing that the oxide layer varied between 90 and $92 \mathrm{~nm}$ in thickness.

Starches: Four different types of starches from Lyckeby Stärkelsen (Kristianstad, Sweden) were used, see Table 1. The cationic potato starch and the anionic potato starch were prepared from ordinary potato starch. The high amylose starch and high amylopectin starch were prepared from plants that had been genetically modified, in order to produce more of each respective component of the starch. The starches were cooked, by heating a $1 \mathrm{~g} / \mathrm{l}$ starch slurry to $95^{\circ} \mathrm{C}$ and maintaining this temperature for 30 minutes before allowing the starch solution to cool down under ambient conditions. Amylose-rich starch was cooked for 45 minutes to achieve complete gelatinisation. The degree of starch gelatinisation was controlled with light microscopy. Fresh solutions of starch were prepared every day to avoid the influence of starch degradation on the starch properties. The charges of the starches were determined using polyelectrolyte titration from which the degree of substitution was calculated (see Table 1). The measurements were performed at Lyckeby Stärkelsen using a streaming current device, the Mütec, PCD 03 particle charge detector.

Other chemicals: The hydrochloric acid, sodium hydroxide, and sodium chloride used in the investigation were all of analytical grade and supplied by Merck.

Table 1. Summary descriptions of the starches used in this investigation. DS = degree of substitution of cationic and anionic groups in the starches.

\begin{tabular}{ll}
\hline Types of starch & D.S. \\
\hline Cationic potato starch (potato) & 0.065 \\
Cationic high amylose potato starch (amylose) & 0.064 \\
Cationic high amylopectine potato starch (amylopectine) & 0.065 \\
Anionic potato starch (AS) & 0.065 \\
\hline
\end{tabular}

\section{Methods}

Stagnation point adsorption reflectometry (SPAR): The formation of starch multilayers with CS and AS was studied using SPAR. The method and its underlying theory is well covered by Dijt et al. (1990) and hence will not be repeated in detail here. With the SPAR technique, the adsorption of polyelectrolyte or surfactant layers onto a flat, optically well-defined surface can be studied under controlled flow conditions. This gives the possibility to study the adsorption kinetics and saturation adsorption as functions of various parameters, such as concentration of adsorbing species, electrolyte concentration, type of electrolyte, and $\mathrm{pH}$. SPAR is based on the principle that the reflectivity of polarised laser light changes as adsorption occurs onto a reflecting surface. A reflectivity ratio, $S$, is defined from the reflectivity of the laser light in both directions of polarisation. From the change of this entity, $\Delta S$, upon polyelectrolyte adsorption, it is possible to calculate an adsorbed amount, $\Gamma$, using a four-layer (silicon, silicon oxide, polymer, and the solvent) optical model, according to $E q$ [1].

$$
\Gamma=\frac{1}{A_{s}} \times \frac{\Delta S}{S}
$$

$A_{\mathrm{s}}$ is a sensitivity factor proportional to the refractive index increment, $d n / d c$, of the adsorbing species. $A_{\mathrm{s}}$ is also highly sensitive to the thickness of the oxide layer on the silicon wafer.

In this investigation, SPAR was used to study the consecutive build-up of CS and AS on silicon oxide surfaces. The data were not converted to a surface excess since a more advanced (and unavailable) theoretical model is required in order to exactly quantify the adsorbed amount. The results were instead presented as a relative change in the reflected signal $(\Delta \mathrm{S} / \mathrm{S})$ and thereby used to monitor the formation of starch multilayers.

In the present experiments silicon oxide surfaces were consecutively treated with CS and AS solutions of 30 $\mathrm{mg} / \mathrm{l}$ concentration at $\mathrm{pH} 7$ in a background solution of $10^{-2} \mathrm{M} \mathrm{NaCl}$, for 5-10 minute intervals, the length of time depending on the particular starch studied. Between each starch treatment, a rinsing step was performed for 5 minutes with a solution of the same electrolyte concentration and $\mathrm{pH}$ as the adsorbing starch solution. When PEM are being formed, it is important to have a rinsing step between each treatment to remove any non-adsorbed polyelectrolyte and to ensure film stability (Hoogeveen et al. 1996).

Fibre treatment: The dried fibres were soaked in deionised water and defibrated in a disintegrator for 30,000 revolutions according to ISO 5263-1:1997. After defibration, the fibres were washed with deionised water and diluted to a final concentration of $0.48 \%$ in a solution of $10^{-2} \mathrm{M} \mathrm{NaCl}$; the $\mathrm{pH}$ was adjusted to 7 .

The fibres were treated with $\mathrm{CS}$ and AS using a procedure described elsewhere (Wågberg et al. 2002). The starch was added to the fibre suspension at an addition level of $45 \mathrm{mg} \mathrm{starch} / \mathrm{g}$ fibre and was allowed to adsorb for 10 minutes before the solution was filtered off via a Büchner funnel fitted with a 100-mesh plastic screen. The filter cake formed was then washed with a small amount of deionised water to remove any unadsorbed excess starch. The starch-treated fibres were again diluted in a $10^{-2} \mathrm{M} \mathrm{NaCl}$ solution to a $0.48 \%$ fibre concentration. The $\mathrm{pH}$ was adjusted to 7 before the next starch addition. After each treatment, some of the fibre suspension was used to prepare sheets while the remaining suspension was treated with the next starch solution.

Sheet preparation: The sheets were prepared with the aid of Rapid Köthen sheet forming equipment supplied by Paper Testing Instruments (PTI), Pettenbach, Austria. In this equipment, sheets with a grammage of $100 \mathrm{~g} / \mathrm{m}^{2}$ 
were formed after thorough fibre dispersion by means of vigorous agitation of the fibre suspension by air jets just prior to sheet formation. The sheets were then pressed at $100 \mathrm{kPa}$ and dried under restrained conditions at $93^{\circ} \mathrm{C}$ for 10 minutes. The ISO/DIS 5269-2:1998 method was followed for sheet preparation.

Paper testing: Tensile testing was conducted according to SCAN P:67.93, while grammage, thickness, and density were all evaluated according to SCAN C 28:76. Scott Bond properties were tested according to Tappi 833 pm-94.

Enzymatic analysis of the sheets: The sheets were analysed for their content of starch, according to an enzymatic procedure presented elsewhere (Wågberg and Björklund 1993) . Lyckeby Stärkelsen kindly performed this analysis.

\section{Results}

\section{The adsorption of starch onto silicon oxide surfaces and fibres}

In order to investigate the possibility to form polyelectrolyte multilayers (PEM) using the different starches (shown in Table 1), the adsorption of starch layers was tested in the SPAR equipment. The relative changes in the reflectometer signal, $\Delta S / S$, for the different combinations of starches are shown in Figs 1-3. First, a stable baseline was established using only the electrolyte solution. The CS was then introduced, followed by a rinsing step. Then the AS was introduced, followed by a second rinsing step before the CS was again introduced, followed by a final rinsing step. The three different combinations all showed an increase in the signal upon starch treatment; this strongly supports the hypothesis that the surface is recharged with each treatment, leading to the formation of a starch multilayer.

From Figs 1-3 it can also be seen that the relative change of the signal differed depending on the type of starch under investigation. The time needed to reach the plateau value in the S signal was also dependent on the

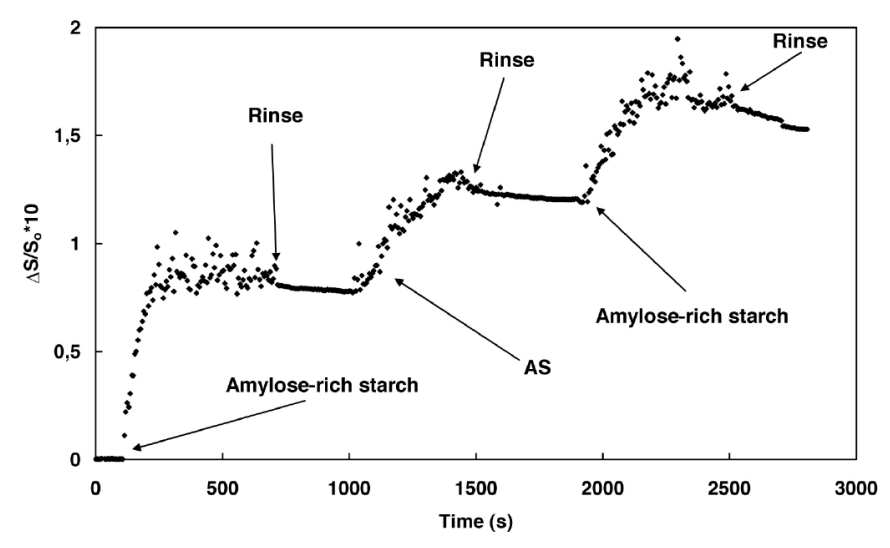

Fig 1. The change in reflectometer signal upon adsorption of cationic potato starch, rich in amylose, onto a silicon oxide surface, followed by adsorption of sulphonated potato starch, and then finally by adsorption of a second layer of cationic potato starch, rich in amylose. A rinsing step between each adsorption was performed in order to remove any excess of starch. The electrolyte concentration was $10^{-2} \mathrm{M} \mathrm{NaCl}$ and the $\mathrm{pH}$ was 7 .

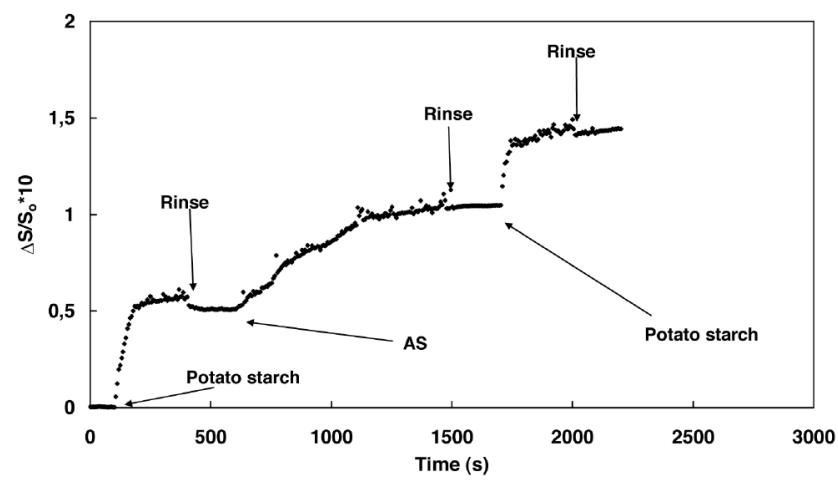

Fig 2. The change in reflectometer signal upon adsorption of cationic potato starch onto a silicon oxide surface, followed by adsorption of sulphonated potato starch, and then finally by adsorption of a second layer of cationic potato starch. A rinsing step between each adsorption was performed in order to remove any excess of starch. The electrolyte concentration was $10^{-2} \mathrm{M} \mathrm{NaCl}$ and the $\mathrm{pH}$ was 7 .

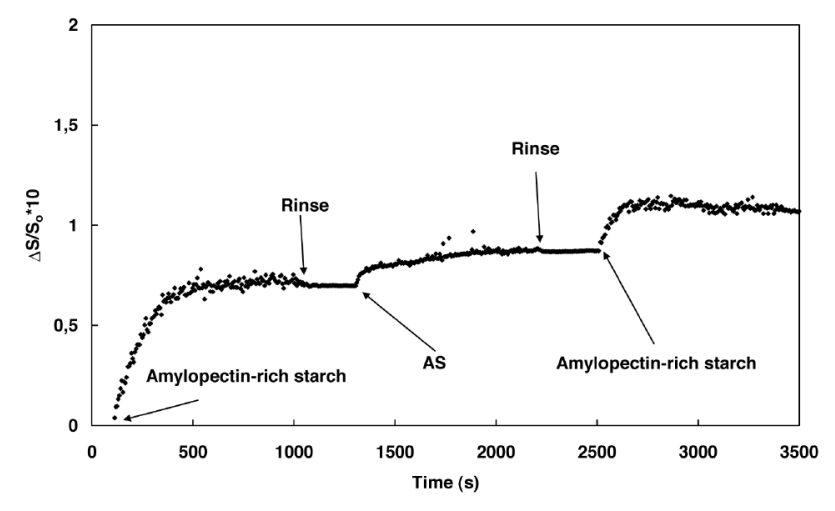

Fig 3. The change in reflectometer signal upon adsorption of cationic potato starch, rich in amylopectin, onto a silicon oxide surface, followed by adsorption of sulphonated potato starch, and then finally by adsorption of a second layer of cationic potato starch, rich in amylopectin. A rinsing step between each adsorption was performed in order to remove any excess starch. The electrolyte concentration was $10^{-2} \mathrm{M} \mathrm{NaCl}$ and the $\mathrm{pH}$ was 7 .

particular starch used. Additionally, the signal was unstable while applying the starches, as opposed to during the rinsing step.

Fig 4 shows the adsorption of starch onto fibres, as determined using an enzymatic method (Wågberg and Björklund 1993). The consecutive treatment of fibres with different starches resulted in the increased adsorption of starch to the fibres. Adsorption onto the fibres was relatively high: $50 \%$ of the added starch was retained in the first and second treatment, while only about $10 \%$ of the starch was retained in the third treatment. The adsorbed amount in the first layer increased with increasing amylose content in CS, whereas in the second layer the adsorbed amount increased when an amylopectin-rich starch was present in the preadsorbed layer. In the third layer the adsorbed amount was higher for amylopectinrich starches.

\section{Strength of sheets prepared from starch-treated fibres}

The use of three different types of CS - amylose-rich, amylopectin-rich, and regular potato starch - allowed studying the importance of the chemical composition of starch to form PEM and to the subsequent enhancement of paper strength. The strength properties of sheets made 


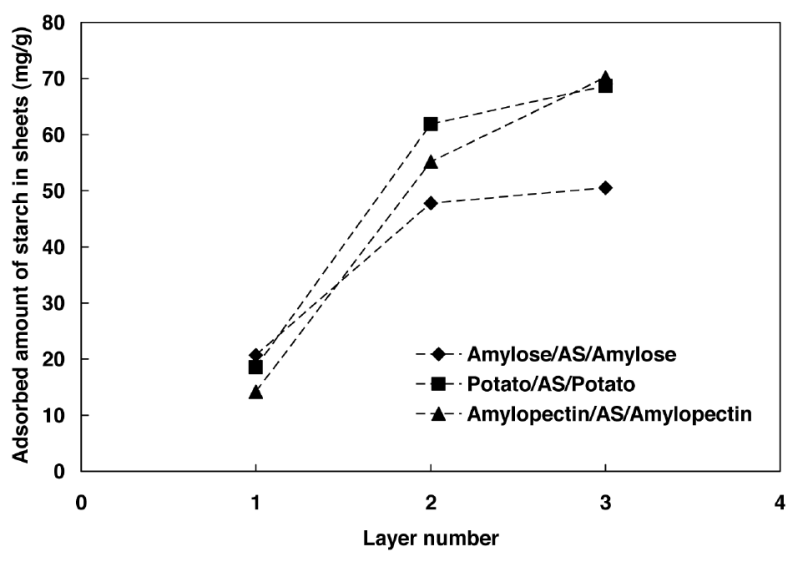

Fig 4. The total adsorbed amount of starch after each treatment, in sheets made of unbeaten bleached softwood pulp, as a function of number of layers (equal to the number of starch treatments). The fibres were treated with CS and AS consecutively to produce three layers, i.e. CS/AS/CS. The multilayer was formed by the addition of $45 \mathrm{mg}$ starch/g fibre in a background electrolyte concentration of $10^{-2} \mathrm{M} \mathrm{NaCl}$ at $\mathrm{pH}$. The AS used in all three series was sulphonated potato starch. The lines included in the figure merely serve to guide the eye.

of untreated fibres were compared to sheets made of fibres with up to three layers of starch. Significant improvements were found in terms of tensile strength, strain at break, and Scott Bond properties for the unbeaten, bleached, softwood kraft fibres used in the investigation. Figs $5 a-c$ show the dependence of paper strength properties on the number of layers. The PEM-treated fibres containing amylose-rich starch showed the most pronounced improvement in terms of both tensile index and strain at break, the strength gradually increasing with each adsorbed layer of starch. The PEM-treated fibres containing amylopectin-rich and potato starches showed an increase in tensile index and strain at break only after the first- and third-layer treatments. When the sulphonated AS was introduced as the external layer, i.e. the second layer treatment, tensile index did not increase; however, strain at break decreased with reference to the preadsorbed layer. The Scott Bond properties increased as the number of layers increased for all series, the potato starch showing the best effects.

\section{Discussion}

\section{Adsorption of starches onto silicon oxide surfaces and fibres}

Silicon oxide surfaces were consecutively treated with cationic and anionic starches in order to test whether PEM could form with both CS and AS. The reflectometer results, as seen in Figs 1-3, showed changes in the reflectometer signal with each starch treatment, clearly indicating PEM formation - as has also been observed in other studied systems (Hoogeveen et al. 1996 Kovacevic et al. 2002).

The changes in the signal should not be directly interpreted as differences in adsorbed amount, since the adsorbed starch layers penetrate/diffuse into adjacent layers, as demonstrated in the case of other polyelectrolyte systems (Decher 1997, Schmitt et al. 1993, Kellogg et al.
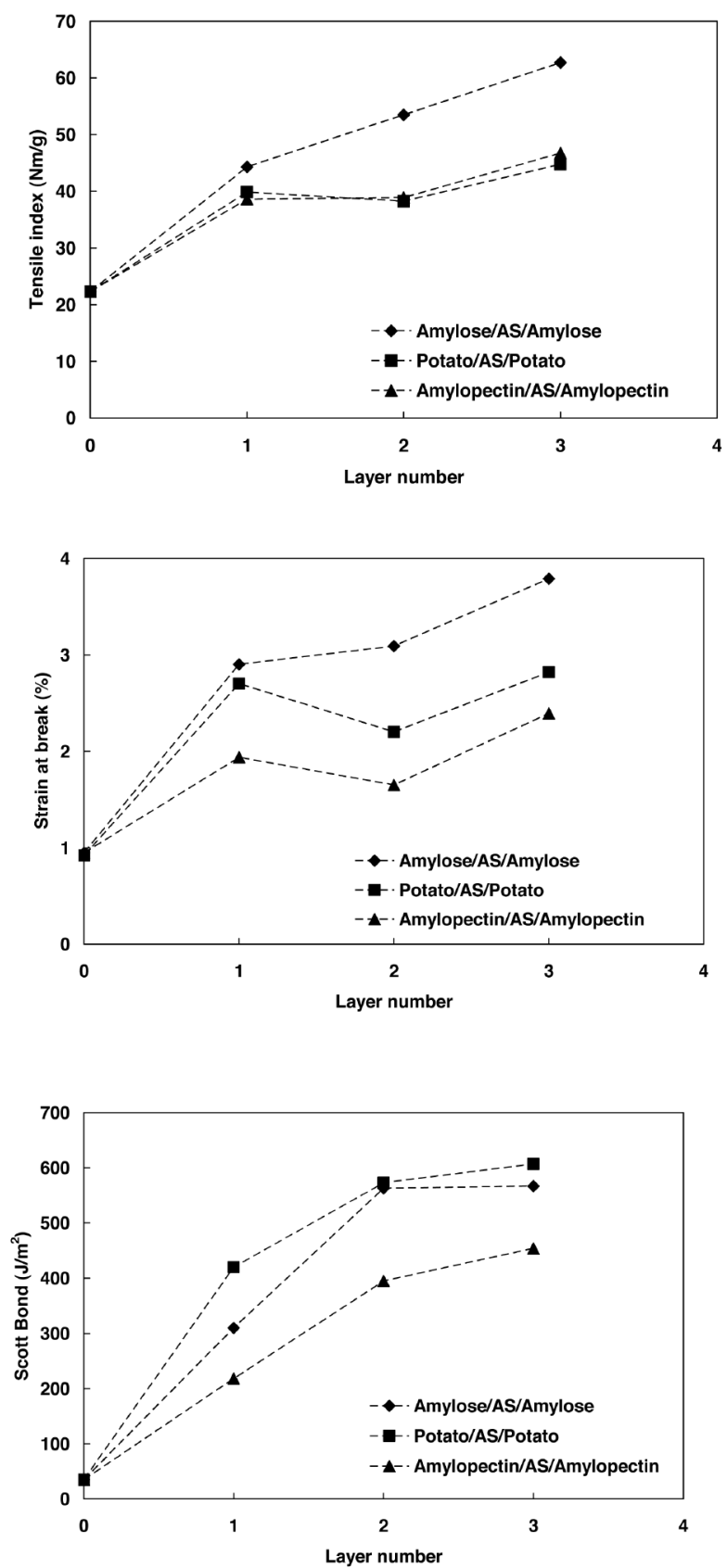

Figs 5a-c. Tensile index, strain at break, and Scott Bond properties of sheets containing different types of starches, as a function of number of layers, which is equal to the number of starch treatments. Sheets were made of unbeaten, bleached, softwood kraft pulp. The fibres were treated with CS and AS consecutively to produce three layers, i.e. CS/AS/CS. The adsorptions were performed by the addition of $45 \mathrm{mg}$ starch/g fibre in a background electrolyte concentration of $10^{-2} \mathrm{M} \mathrm{NaCl}$ at $\mathrm{pH}$ 7. The AS used in all three series was sulphonated potato starch. The lines included in the figure merely serve to guide the eye.

1996). This results in a film with a new refractive index increment $(d n / d c)$ value, probably in the same range as the two components. Since it has not been possible to determine the combined $d n / d c$ values of the starches used in this study, the reflectometer signal was only used for qualitatively evaluating PEM formation and not for quantitatively determining the adsorbed amount.

The baseline instability observed during starch treatment could be due to the fact that the starch was highly polydisperse and contained some larger fragments, possibly residual products of the starch granules. These 
were significantly larger than the actual polyelectrolyte and probably did not adhere to the surface. However, their presence would create refractive index gradients in the solution that could disturb the reflected signal. The stable baseline observed during the rinsing step, in which no starch was present, supports this explanation.

It is of interest to compare adsorption onto the silicon oxide surfaces, as detected with the reflectometer signal, to the amount adsorbed onto the fibres. Table 2 presents a summary of the data contained in Figs 1-4. As can be seen from the table, it is no simple task to qualitatively transfer data from the SPAR experiments to the adsorption onto the fibres. This could have several explanations, and cannot be explained solely by the $d n / d c$ values of the different starches, since the $d n / d c$ of amylose and amylopectin in the same solvent do not differ substantially (Stacy and Foster 1956, Paschall and Foster 1952). Considering the differences between the starches in terms of adsorption onto silicon oxide and fibres, it is more likely that the differences are due to the geometry of the surface and the physical properties of the starches used. Since fibres are porous, it is likely that some starches with lower molecular mass could penetrate more deeply into the fibre wall. Furthermore, it is likely that the ability of a starch of lower molecular mass to recharge a flat silicon oxide surface differs from its ability to recharge a nanoporous fibre wall.

The larger amount of amylose-rich starch than other starches adsorbed in the first layer was probably caused by the difference in molecular size between the starches used. The smaller amylose molecules might be able to reach charges within the fibre wall and not only charges on the fibre surface, as would be expected of the larger amylopectin molecules. Adsorption of the second layer would mainly depend on the ability of the first starch layer to recharge the anionic surface. In both Fig 4 and Table 2 it can be seen that amylose-rich starch was less efficient at recharging the surface, since adsorption in the second layer was significantly lower for the amylosecovered fibres. The observed difference in the ratio of adsorbed amount in the first and second layers, between amylose-rich starch and the other starches, was probably due to the inaccessibility of the AS to the amylose within the fibre wall. The amylopectin, which probably adsorbed mainly onto the fibre surface due to the very large size of its molecules, most probably acted as a better recharger of the surface. Hence more anionic starch could be adsorbed when an amylopectin-rich layer was preadsorbed. Since potato starch contains about $75 \%$ amylopectin, this explanation could also apply to the potato starch. The

Table 2. Comparison between changes in reflectometer signal and values from the adsorbed amount of starches in the sheets during formation of PEM, which comprises three layers, i.e. CS/AS/CS. In the table, each series is named after the CS used during the PEM formation.

\begin{tabular}{lcccccc}
\hline $\begin{array}{l}\text { Layer } \\
\text { number }\end{array}$ & $\begin{array}{c}\text { Amylose } \\
\Delta \mathrm{S} / \mathrm{S}\end{array}$ & $\begin{array}{c}\text { Amylose } \\
\mathrm{mg} / \mathrm{g}\end{array}$ & $\begin{array}{c}\text { Potato } \\
\Delta \mathrm{S} / \mathrm{S}\end{array}$ & $\begin{array}{c}\text { Potato } \\
\mathrm{mg} / \mathrm{g}\end{array}$ & $\begin{array}{c}\text { Amylopectine } \\
\Delta \mathrm{S} / \mathrm{S}\end{array}$ & $\begin{array}{c}\text { Amylopectine } \\
\mathrm{mg} / \mathrm{g}\end{array}$ \\
\hline 1 (CS) & 0.79 & 21 & 0.58 & 19 & 0.72 & 14 \\
2 (AS) & 0.42 & 27 & 0.45 & 43 & 0.16 & 41 \\
3 (CS) & 0.47 & 2.7 & 0.40 & 6.8 & 0.22 & 15 \\
\hline
\end{tabular}

pronounced drop in adsorption in the third layer for all starches is more difficult to explain, and could have several explanations. It is known that a certain charge density and salt concentration is needed for a stable PEM to form (Glinel et al. 2002, Voigt et al. 2003, Schlenoff et al. 1998, Hoogeveen et al. 1996). It is also known that the substrate does not influence adsorption after deposition of the first few layers, after which the charge balance between the polyelectrolytes dominates PEM formation (Hoogeveen et al. 1996). These results hence indicate that more experiments are needed to uncover the exact mechanisms of starch PEM formation for higher-numbered layers.

\section{Influence of adsorbed amount of starch on strength properties of paper}

As was demonstrated in Figs $5 a-c$, PEM treatment of the fibres considerably improved the strength of the sheets. However, in order to separate the properties of the layers from the efficiency by which the different starches adsorb onto the fibres, it is necessary to show the strength properties as a function of adsorbed amount in the sheets. Figs $6 a-c$ show how the adsorbed amount influences the strength properties, and several interesting phenomena are demonstrated. First, amylose-rich starch resulted in the best strength-enhancement in terms of tensile index and strain at break at a given adsorbed amount. Second, the AS used in the second layer had a rather low strength-enhancing effect; however, the strength enhancement was again higher for the starch adsorbed in the third layer. Finally, regarding Scott Bond values, potato starch and amylose-rich starch produced similar results.

There may be several explanations of these differences, but the mechanical properties of the layers as such and their ability to anchor to the porous fibres are likely the most important factors. It is known that films cast from pure amylose are elastic and that films cast from amylopectin are very brittle (Olle Wikström, Lyckeby Stärkelsen, private communication). This affects the mechanical properties of the sheets, since the sheet strength is limited by the adhesion between the unbeaten fibres used. Furthermore, amylose may penetrate the fibre wall, thereby anchoring itself more securely, allowing for better use of the mechanical properties of the fibre wall during tensile testing. It is also possible that the out-of-plane mechanical properties, as determined by the Scott Bond measurements, are more affected by the cohesive properties of the films. This could explain why the potato starch- and amylopectin-treated sheets displayed approximately the same strength enhancement in terms of Scott Bond values as did the amylose-treated sheets. These hypotheses must be tested in future experiments in which the mechanical properties of PEM films of different compositions are determined, and the adhesive properties of these films are determined via micro-adhesion measurements. Both kinds of model studies are currently underway in the authors' laboratory.

Finally, it is interesting to note that the level of strength achievable with three layers of starch is better than that 

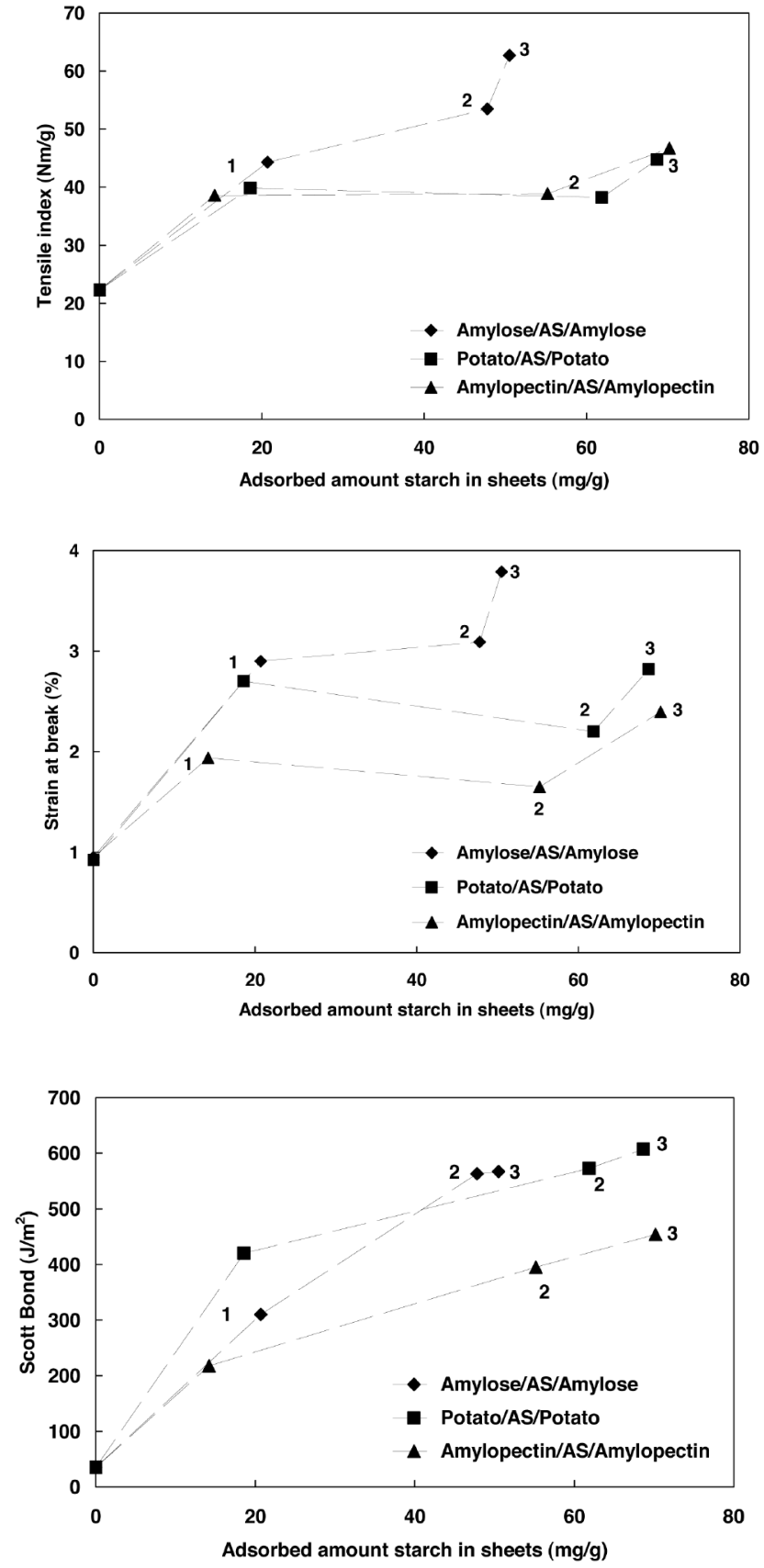

Figs $6 \mathrm{a}-\mathrm{c}$. Tensile index, strain at break, and Scott Bond properties of sheets made of an unbeaten, bleached, softwood pulp as a function of total adsorbed amount of starch after each starch treatment. Adsorption of starches onto the fibres prior sheet formation was performed as outlined in Figure $5 \mathrm{a}$-c. The AS used in all three series was sulphonated potato starch. The numbers included in the figure refer to the number of treatments, while the lines merely serve to guide the eye.

achievable with 10 layers of polyallylamine hydrochloride and polyacrylic acid (Wågberg et al. 2002). This is a clear indication of the great potential of multilayer starch treatment.

\section{Conclusions}

The present study shows that starch multilayer treatment is a very attractive way of increasing the strengthimproving potential of starch additions in various papermaking applications.

A pre-study of starch adsorption using SPAR revealed the possibility of building PEM with cationic and anionic starches. When the cationic starches were in the outermost layer of the fibre treatment, i.e. the first or third layer, improvement in all investigated strength properties was detected. When the anionic potato starch was in the outermost layer, little or no increase in tensile index and strain at break was detected, despite the high adsorbed amount. The anionic starch significantly improved strength in terms of the out-of-plane properties of the sheets. Furthermore, for this property there was a nearly linear relationship between strength and adsorbed amount. The amylose-rich starch resulted in the best effects on the in-plane paper strength properties. These findings suggest that the strength properties are increased not simply because the PEM approach allows far more starch to be adsorbed onto the fibres than can a single starch treatment. Strength might also be affected by the properties of the different types of PEM used in this investigation and by the way in which the layers are anchored to the fibre surface and into the fibre wall.

\section{Acknowledgements}

The authors, and especially Gunilla Pettersson, would like to thank Lyckeby Stärkelsen for financial support of this project. Malin Eriksson acknowledges KTH for financial support. The authors would also like to thank others at Lyckeby Stärkelsen for their assistance: Lena Pettersson for her skilled laboratory work, and Eva Larsson and Olle Wikström for their unwavering encouragement, given through valuable comments and discussion. Furthermore STFI, the Swedish Pulp and Paper Research Institute is acknowledged for access to paper testing facilities.

\section{Literature}

Decher, G. (1997): Fuzzy Nano-assemblies:Toward layered polymeric multicomposites, Science, 277, 1232.

Dijt, J. C., Cohen Stuart, M. A., Hofman, J. E. and Fleer, G. J. (1990): Kinetics of polymer adsorption in stagnation point flow, Colloids and Surfaces, 51, 141

Formento, J. C., Maximino, M. G., Mina, L. R., Srayh, M. I. and Martinez, M. J. (1994): Cationic starch in the wet end: Its contribution to interfiber bonding, Appita J. 47(4), 305.

Gaspar, L. A. (1982): Intrinsic bonding of cationic starch and application of cationic starch with recycled fiber, Annual Meeting Proceedings - Technical Association of the Pulp and Paper Industry, Bridgewater, NJ, USA, 89.

Glinel, K., Moussa, A., Jonas, A. M. and Laschewsky, A. (2002): Influence of Polyelectrolyte Charge Density on the Formation of Multilayers of Strong Polyelectrolytes at Low lonic Strength, Langmuir, 18(4), 1408.

Hoogeveen, N. G., Stuart, M. A. C., Fleer, G. J. and Boehmer, M. R. (1996): Formation and Stability of Multilayers of Polyelectrolytes, Langmuir, 12(15), 3675. Howard, R. C. and Jowsey, C. J. (1989): The effect of cationic starch on the tensile strength of paper, J. Pulp Pap. Sci. 15(6), J225.

Kellogg, G. J., Mayes, A. M., Stockton, W. B., Ferreira, M., Rubner, M. F. and Satija, S. K. (1996): Neutron reflectivity investigation of self assembled conjugated polyion multilayers, Langmuir, 12, 5109

Kovacevic, D., Van Der Burgh, S., De Keizer, A. and Stuart, M. A. C. (2002): Kinetics of Formation and Dissolution of Weak Polyelectrolyte Multilayers: Role of Salt and Free Polyions, Langmuir, 18(14), 5607.

Laleg, M. L., Pikulik, I. I., Ono, H., Barbe, M. C. and Seth, R. S. (1991): The effect of starch on the properties of groundwood papers, Paper Technology, 32(5), 24. Lindström, T. and Floren, T. (1984): The effects of cationic starch wet end addition on the properties of clay filled papers, Svensk Papperstidn. 87(12), R99. Moeller, H. W. (1966): Cationic starch as a wet-end strength additive, Tappi, 49(5), 211. Paschall, E. F. and Foster, J. F. (1952): Further studies by light scattering of amylose aggregates. Particle weights under various conditions, J. Polym. Sci. 9, 85. 
Retulainen, E., Nieminen, K. and Nurminen, I. (1993): Enhancing strength properties of kraft and CTMP fiber networks, Appita J. 46(1), 33.

Schlenoff, J. B., Ly, H. and Li, M. (1998): Charge and mass Balance in polyelectrolyte multilayers, J. of American Chem. Society, 120, 7626.

Schmitt, J., Grunewald, T., Decher, G., Pershan, P. S., Kjaer, K. and Losche, M. (1993): Internal structure of layer-by-layer adsorbed polyelectrolyte films: A neutron and x-ray reflectivity study, Macromolecules, 26, 7058.

Stacy, C. J. and Foster, J. F. (1956): A light scattering study of corn amylopectin and its beta-amylase limit dextrin, J. Polym. Sci. 20, 57.

Sun, Y., Zhang, X., Sun, C., Wang, B. and Shen, J. (1996): Fabrication of ultrathin film containing bienzyme of glucose oxidase and glucoamylase based on electrostatic interaction and its potential application as a maltose sensor, Macromolecules Chemistry and Physics, 197, 147.

Van De Steeg, H. G. M., De Keizer, A., Cohen Stuart, M. A. and Bijsterbosch, B. H. (1993a): Adsorption of cationic amylopectin on microcrystalline cellulose. Colloids and Surfaces, A: Physicochemical and Engineering Aspects, 70(1), 77.

Van De Steeg, H. G. M., De Keizer, A., Stuart, M. A. C. and Bijsterbosch, B. H. (1993b): Adsorption of cationic starches on microcrystalline cellulose, Nordic Pulp Pap. Res. J. 8(1), 34

Voigt, U., Jaeger, W., Findenegg, G. H. and Von Klitzing, R. (2003): Charge Effects on the Formation of Multilayers Containing Strong Polyelectrolytes, J. Phys. Chem. B, 107(22), 5273.

(1993): Adsorption of cationic potato starch on cellulosic fibers, Nordic Pulp Pap. Res. J. 8(4), 399.

Wågberg, L. and Björklund, M. (1993): Adsorption of cationic potato starch on cellulosic fibers, Nordic Pulp Pap. Res. J. 8(4), 399.

Wågberg, L., Forsberg, S., Johansson, A. and Juntti, P. (2002): Engineering of fibre surface properties by application of the polyelectrolyte multilayer concept. Part I. Modification of paper strength, J. Pulp Pap. Sci. 28, 222.

Wågberg, L. and Kolar, K. (1996): Adsorption of cationic starch on fibers from mechanical pulps, Berichte der Bunsen-Gesellschaft, 100(6), 984

Manuscript received November 11, 2004 Accepted March, 2005 